\title{
Effects of Glucose Repression and Anaerobiosis on the Activities and Subcellular Distribution of Tricarboxylic Acid Cycle and Associated Enzymes in Saccharomyces carlsbergensis
}

\author{
By DAVID S. WALES, ${ }^{1}$ TREVOR G. CARTLEDGE ${ }^{1}$ \\ AND DAVID LLOYD ${ }^{2}$ \\ ${ }^{1}$ Department of Life Sciences, Trent Polytechnic, Nottingham NG1 $4 B U$ \\ ${ }^{2}$ Department of Microbiology, University College, Cardiff CF2 1TA
}

(Received 30 March 1979; revised 23 May 1979)

\begin{abstract}
Cell-free extracts were prepared from sphaeroplasts of aerobically and anaerobically grown, glucose-derepressed and glucose-repressed Saccharomyces carlsbergensis. The activities of the enzymes of the tricarboxylic acid cycle and of related enzymes were measured, together with their distributions after differential centrifugation. Glucose repression lowered activities of enzymes of the tricarboxylic acid cycle by 60 to $89 \%$ under aerobic conditions. Activities were still further decreased under anaerobic glucose-derepressed conditions. 2-Oxoglutarate decarboxylase activity was not detected after anaerobic growth; malate synthase and isocitrate lyase activities were not detected in organisms grown either aerobically or anaerobically. Glucose had little effect on the activities of tricarboxylic acid cycle enzymes under anaerobic conditions, with the exception of citrate synthase whose activity increased under anaerobic glucose-repressed conditions. Differential centrifugation of cell-free extracts showed different distribution patterns of the enzymes under the four growth conditions. The distribution patterns and enzyme activities reflected the differential effects of glucose repression and/or anaerobiosis.
\end{abstract}

\section{INTRODUCTION}

The cytochrome contents and activities of electron transport chain and associated enzymes of mitochondria from Saccharomyces species are altered substantially by the presence of a repressing carbon source (e.g. glucose) and/or anaerobic conditions during growth (Schatz, 1965; Criddle \& Schatz, 1969; Cartledge \& Lloyd, 1972a, $b, c$ ). These authors also showed that differential or zonal centrifugation of cell-free extracts from either glucoserepressed or anaerobically grown cells revealed different distribution patterns of cytochromes and enzymes, when compared with those of cells grown aerobically with derepressing amounts of glucose.

Despite the wealth of information available about the electron transport chain components, little has been published concerning activities and distributions of enzymes of the tricarboxylic acid cycle under these conditions. Polakis \& Bartley (1965) showed lower activities of all enzymes of the tricarboxylic acid cycle present under supposedly repressed conditions $[0.9 \%(\mathrm{w} / \mathrm{v})$ glucose $]$ when compared with derepressed conditions $[0.9 \%(\mathrm{w} / \mathrm{v})$ galactose], using aerobically grown Saccharomyces cerevisiae. Similar results were found for various enzymes of the tricarboxylic acid cycle by Duntze et al. (1969) and Perlman \& Mahler (1974), although again low glucose concentrations were used to achieve repression. Vary et al. (1969) found lowered activities of fumarase and malate and succinate dehydrogenases in anaerobically grown $S$. cerevisiae.

In this paper, we present results for the activities and subcellular distributions of the 
tricarboxylic acid cycle and associated enzymes from cell-free extracts of $S$. carlsbergensis, after growth under the following conditions: (i) aerobic derepressed, (ii) aerobic repressed, (iii) anaerobic derepressed and (iv) anaerobic repressed.

\section{METHODS}

Maintenance and growth. Saccharomyces carlsbergensis (NCYC 74S) was maintained on potato dextrose agar slopes. The complex medium for aerobically grown cultures was that of Duell et al. (1964). Batch cultures (41) were grown in a 51 fermenter (L.H. Engineering Co., Stoke Poges, Bucks.) at $30^{\circ} \mathrm{C}$, with forced aeration ( 41 air $\mathrm{min}^{-1}$, stirring rate $300 \mathrm{rev} \cdot \mathrm{min}^{-1}$ ). The complex medium and method of growth of anaerobic cultures were as described by Cartledge \& Lloyd (1972c) except that the batch cultures (1.5 l) were grown in 21 Quickfit growth vessels (Gallenkamp) in an anaerobic cabinet.

Glucose was added at 0.8 and $10 \%(\mathrm{w} / \mathrm{v})$ for derepressed and repressed conditions, respectively. Starter cultures were grown in $100 \mathrm{ml}$ medium in $250 \mathrm{ml}$ conical flasks shaken for $22 \mathrm{~h}$ at $30^{\circ} \mathrm{C}$ in a rotary orbital incubator (Gallenkamp).

Organisms were counted in an Improved Neubauer haemocytometer (Hawksley, Lancing, Sussex) after suitable dilution and mixing to separate clumps. Batch cultures were harvested in late-exponential or early-

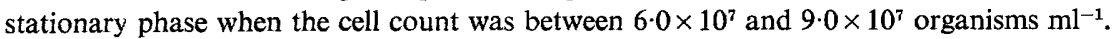

Harvesting, preparation and disruption of sphaeroplasts. Sphaeroplasts were formed as described by Cartledge \& Lloyd (1972a) for aerobic cultures and Cartledge \& Lloyd (1972c) for anaerobic cultures. Partially digested cells, intact sphaeroplasts and nuclei were removed by centrifugation $(2000 \mathrm{~g}, 5 \mathrm{~min})$ in an $8 \times 50 \mathrm{ml}$ rotor of an MSE 18 centrifuge, and the supernatant fraction (cell-free extract) was retained.

Fractionation of cell-free extracts by differential centrifugation. All centrifugation procedures were carried out in the $8 \times 50 \mathrm{ml}$ rotor of an MSE 18 centrifuge at $4^{\circ} \mathrm{C}$. Cell-free extract $(10$ to $20 \mathrm{ml})$ was centrifuged $(10000 \mathrm{~g}, 10 \mathrm{~min})$ and the supernatant was retained. The pellet was resuspended in $5 \mathrm{ml}$ of disruption buffer $\left(0.25 \mathrm{M}\right.$-sucrose, $2 \mathrm{~mm}-\mathrm{MgCl}_{2}$ and $\left.10 \mathrm{~mm}-\mathrm{Tris} / \mathrm{HCl}, \mathrm{pH} 7.4\right)$, and the above procedure was repeated. The supernatants were combined, and the pellet (P1) was resuspended to a known volume in disruption buffer. The combined supernatants were centrifuged $(20000 \mathrm{~g}, 20 \mathrm{~min})$, the resulting supernatant was retained and the pellet was washed in disruption buffer as before. The pellet (P2) was resuspended in disruption buffer to a known volume, and the volume of the final supernatant (FS) was measured.

Enzyme assays. Spectrophotometric assays were carried out at $30^{\circ} \mathrm{C}$. The following enzymes were assayed by previously published methods: citrate synthase (EC 4.1.3.7) (Srere et al., 1963); aconitase (EC 4.2.1.3) (Fansler \& Lowenstein, 1969); alcohol dehydrogenase (EC 1.1.1.1) (Kersters \& De Ley, 1966); L-lactate dehydrogenase (EC 1 1.2.3) (Symons \& Burcoyne, 1966); malate synthase (EC 4.1.3.2) and isocitrate lyase (EC 4.1.3.1) (Dixon \& Kornberg, 1959); fumarate reductase (Massey \& Singer, 1957). Malate dehydrogenase (EC 1.1 .1 .37 ) was assayed as described by Kitto (1969) except that $0 \cdot 1 \mathrm{M}$-potassium phosphate buffer, $\mathrm{pH} 7 \cdot 8$, was used. Fumarase (EC 4.2.1.2) was assayed by the method of Racker (1950), except that $0.03 \mathrm{M}$ potassium phosphate buffer, $\mathrm{pH} 7 \cdot 8$, was used. NADP-linked isocitrate dehydrogenase (EC 1.1.1.42) was assayed in a reaction mixture containing $1.8 \mathrm{mM}$-DL-isocitrate, $131 \mu \mathrm{M}$-NADP, $600 \mu \mathrm{M}$-manganese chloride and $0.03 \mathrm{M}$-potassium phosphate buffer, $\mathrm{pH}$ 7.2. Succinate dehydrogenase (EC 1.3.99.1) was assayed in a reaction mixture containing $13.3 \mathrm{~mm}$-sodium succinate, $8.61 \mu \mathrm{M}$-dichlorophenolindophenol, $2.2 \mathrm{~mm}$ phenazine methosulphate, $33.3 \mathrm{~mm}$-potassium cyanide and $0.1 \mathrm{M}$-potassium phosphate buffer, $\mathrm{pH} 7.5$. 2-Oxoglutarate decarboxylase, part of the 2-oxoglutarate dehydrogenase complex, was assayed by the reduction of ferricyanide, which, in turn, was measured as Prussian Blue by the colorimetric method of Reed $\&$ Willms (1966). The reaction mixture contained $35.7 \mathrm{~mm}$-2-oxoglutarate, $143 \mu \mathrm{M}$-thiamin pyrophosphate, $214 \mu \mathrm{M}$-magnesium sulphate, $17.8 \mathrm{mM}$-potassium ferricyanide and $0.11 \mathrm{M}$-potassium phosphate buffer, pH 7.0. The decarboxylase was assayed in preference to the dehydrogenase complex as the decarboxylase assay was found to be more reliable.

Preliminary experiments were done with cell-free extracts to ensure that the rates of enzyme reactions measured were proportional to the amount of extract protein used, were not limited by substrate concentration and were assayed at optimum $\mathrm{pH}$. Where necessary, appropriate dilutions of cell-free extracts and fractions were used to obtain a suitable enzyme rate, and the validity of the assays was confirmed by the satisfactory enzyme recovery values finally obtained.

The results presented are averages of at least three experiments.

Protein was measured by the Lowry method, with bovine serum albumin as a standard.

Chemicals. Potassium ferrocyanide, potassium ferricyanide, ethanol, sodium dithionite and glucose were from $\mathrm{BDH}$; other substrates were from Sigma. 
Table 1. Specific activities of the tricarboxylic acid cycle and related enzymes in cell-free extracts of Saccharomyces carlsbergensis grown under four different conditions

Figures in parentheses show the specific activities expressed as a percentage of the corresponding activity for growth under aerobic, glucose-derepressed conditions.

\begin{tabular}{|c|c|c|c|c|}
\hline \multirow[b]{2}{*}{ Enzyme } & \multicolumn{4}{|c|}{ Enzyme specific activity [ $\left.\mathrm{nmol} \mathrm{min}^{-1}(\mathrm{mg} \text { protein })^{-1}\right]$} \\
\hline & $\begin{array}{c}\text { Aerobic, } \\
\text { glucose- } \\
\text { derepressed }\end{array}$ & $\begin{array}{l}\text { Aerobic, } \\
\text { glucose- } \\
\text { repressed }\end{array}$ & $\begin{array}{l}\text { Anaerobic, } \\
\text { glucose- } \\
\text { derepressed }\end{array}$ & $\begin{array}{l}\text { Anaerobic, } \\
\text { glucose- } \\
\text { repressed }\end{array}$ \\
\hline Citrate synthase & 128 & $13(11)$ & $7(5)$ & $44(34)$ \\
\hline Aconitase & 221 & $49(22)$ & $19(9)$ & $1(0 \cdot 3)$ \\
\hline NADP-linked isocitrate dehydrogenase & 94 & $35(37)$ & $10(11)$ & $14(15)$ \\
\hline 2-Oxoglutarate decarboxylase & 27 & $4(16)$ & $<0 \cdot 3(0)$ & $<0.3(0)$ \\
\hline Succinate dehydrogenase & 44 & $6(14)$ & $1(2)$ & $1(3)$ \\
\hline Fumarase & 510 & $98(19)$ & $2(0 \cdot 3)$ & $3(0 \cdot 5)$ \\
\hline Malate dehydrogenase & 4120 & $1630(40)$ & $175(4)$ & $155(3)$ \\
\hline Alcohol dehydrogenase & 1380 & $1680(122)$ & $93(7)$ & $1040(76)$ \\
\hline L-Lactate dehydrogenase & 148 & $23(15)$ & $5(3)$ & $3(2)$ \\
\hline Fumarate reductase & 73 & $125(170)$ & $12(16)$ & $8(11)$ \\
\hline Isocitrate lyase & ND & ND & ND & ND \\
\hline Malate synthase & ND & ND & ND & ND \\
\hline
\end{tabular}

ND, Not detectable.

\section{RESULTS}

\section{Characterization of fractions}

Previous studies of cytochrome $c$ oxidase distribution (Cartledge \& Lloyd, 1972a) indicated that mitochondria from sphaeroplasts of Saccharomyces carlsbergensis are completely sedimented in fractions P1 and P2. Cytochrome $c$ oxidase, however, is undetectable in cell-free extracts of anaerobically grown organisms (Cartledge \& Lloyd, 1972c) and in this case the presence of mitochondria-like organelles only in P1 and P2 fractions is indicated by the complete recovery of oligomycin-sensitive ATPase in these fractions.

\section{Enzyme activities in cell-free extracts}

The highest activities of enzymes of the tricarboxylic acid cycle occurred in the cell-free extracts of aerobically grown, glucose-derepressed organisms (Table 1). These activities were 60 to $89 \%$ lower in extracts of aerobically grown, glucose-repressed organisms and, except for citrate synthase, the activities were even lower in extracts after anaerobic growth. Citrate synthase behaved differently in that its activity in extracts of anaerobically grown, glucose-repressed organisms was higher than in extracts of either anaerobically grown, glucose-derepressed or aerobically grown, glucose-repressed organisms. 2-Oxoglutarate decarboxylase activity was not detected in extracts obtained from organisms grown under either of the anaerobic conditions. L-Lactate dehydrogenase activities followed the same pattern as the majority of enzymes of the tricarboxylic acid cycle, i.e. those other than citrate synthase.

Alcohol dehydrogenase was more active in extracts from aerobically grown, glucoserepressed organisms than in extracts from aerobically grown, glucose-derepressed organisms. The lowest activity occurred in the anaerobically grown, glucose-derepressed extracts. Fumarate reductase behaved similarly to alcohol dehydrogenase under aerobic conditions.

Malate synthase and isocitrate lyase activities could not be detected in extracts of organisms grown under any of the four growth conditions. 

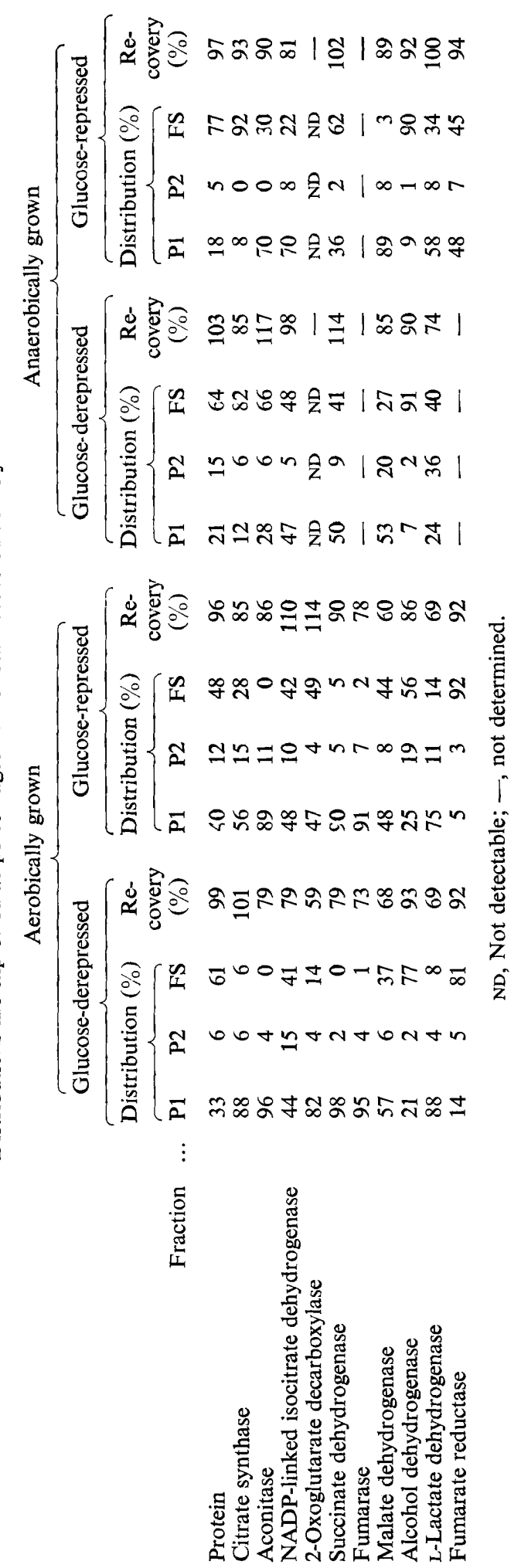


\section{Fractionation of cell-free extracts by differential centrifugation}

With the exception of NADP-linked isocitrate dehydrogenase (44\%) and malate dehydrogenase $(57 \%)$, over $80 \%$ of the recovered activities of the enzymes of the tricarboxylic acid cycle and L-lactate dehydrogenase were found in fraction P1 from the extracts of aerobically grown, glucose-derepressed organisms (Table 2). The alcohol dehydrogenase and fumarate reductase distributions were in complete contrast to the other enzymes, a higher percentage of the recovered activity occurring in the final supernatant.

Results from an extract of aerobically grown, glucose-repressed organisms showed that most of the recovered activity (about $90 \%$ ) of fumarase, succinate dehydrogenase, aconitase and L-lactate dehydrogenase occurred in fraction P1. Lower percentages of the recovered activity of citrate synthase, 2-oxoglutarate decarboxylase and malate dehydrogenase (56, 47 and 48, respectively) were found in fraction Pl under these conditions. Conversely, a high percentage of the recovered activity of alcohol dehydrogenase and fumarate reductase occurred in fraction FS.

With the exception of malate dehydrogenase ( $53 \%$ ), fraction P1 of extracts from anaerobically grown, glucose-derepressed organisms contained less than $50 \%$ of the recovered activity of each enzyme. This decrease in recovered enzyme activities in fraction P1 (compared with this fraction from organisms grown under both aerobic conditions) was accompanied by a decrease to $21 \%$ of recovered protein. The percentage of recovered activities of several enzymes in fraction P1 was much higher in extracts from anaerobically grown, glucose-repressed organisms (malate dehydrogenase $89 \%$, aconitase and NADP-linked isocitrate dehydrogenase both $70 \%$, and L-lactate dehydrogenase $58 \%$ ). Citrate synthase and alcohol dehydrogenase activities were almost entirely recovered in fraction FS.

\section{DISCUSSION}

The comparative values of specific activities (in parentheses, Table 1) show a distinct trend under the four conditions of growth. There is a decrease in activity of enzymes of the tricarboxylic acid cycle with glucose repression (see also Polakis \& Bartley, 1965; Duntze et al., 1969; Perlman \& Mahler, 1974) and a further reduction in activities under anaerobic conditions. 2-Oxoglutarate decarboxylase activity was not found under anaerobic conditions. Machado et al. (1975) found low activities of 2-oxoglutarate dehydrogenase under 'hypoxic' conditions and suggested that the tricarboxylic acid cycle is modified to provide a branched, non-cyclic pathway, first reported in Escherichia coli (Amarasingham \& Davis, 1965). Fumarate reductase is present, although with low activity, under anaerobic conditions.

A much higher activity of alcohol dehydrogenase was present under aerobic derepressed conditions, and a higher percentage of the activity was located in fraction P1, compared with organisms grown anaerobically. Ball et al. (1975) also found an increase in alcohol dehydrogenase activity during aerobic adaptation (with derepressing amounts of glucose) and suggested that repression of cytoplasmic alcohol dehydrogenase followed by an induction of mitochondrial alcohol dehydrogenase occurred.

The lower recovered activities of some of the enzymes of the tricarboxylic acid cycle in fraction P1 of aerobically grown, glucose-repressed organisms, and their even lower activities under anaerobic derepressed conditions, can perhaps be explained by the matrix enzymes leaching out of the more fragile promitochondria (Criddle \& Schatz, 1969; Dansky, 1976) during the preparation of the fractions. However, the fact that integral proteins such as 2-oxoglutarate dehydrogenase and succinate dehydrogenase [which is bound to the mitochondrial membrane (Singer \& Nicholson, 1972)] are only partly sedimentable is more difficult to explain.

Chapman \& Bartley (1968) have shown that adaptation of yeast to both conditions of glucose repression and anaerobiosis lowers the activities of enzymes of the tricarboxylic acid cycle, but concluded that the glucose concentration is the major effector of this. How- 
ever, the main conclusion to be drawn from our results is that glucose repression and anaerobiosis show the same qualitative effects on the enzymes studied, but quantitatively the effects of anaerobiosis are much more marked.

This work was carried out during the tenure of a Science Research Council Postgraduate Studentship by D.S.W.

\section{REFERENCES}

Amarasingham, C. R. \& Davis, B. D. (1965). Regulation of $\alpha$-ketoglutarate dehydrogenase formation in Escherichia coli. Journal of Biological Chemistry 240, 3664-3668.

Ball, A. J. S., Bruver, R. M. \& Tustanoff, E. R. (1975). Aerobic adaption in yeast. II. Changes in enzyme profiles during step-down anaerobicaerobic transfer. Canadian Journal of Microbiology 21, 855-861.

Cartledge, T. G. \& Lloyd, D. (1972a). Subcellular fractionation by differential and zonal centrifugation of aerobically grown glucose-derepressed Saccharomyces carlsbergensis. Biochemical Journal 126, 381-393.

Cartledge, T. G. \& Lloyd, D. (1972b). Subcellular fractionation of particles containing acid hydrolases from Saccharomyces carlsbergensis. Biochemical Journal 126, 755-757.

Cartledge, T. G. \& Lloyd, D. (1972c). Subcellular fractionation by zonal centrifugation of glucoserepressed anaerobically grown Saccharomyces carlsbergensis. Biochemical Journal 127, 693703.

Chapman, C. \& Bartley, W. (1968). The kinetics of enzyme changes in yeast under conditions that cause the loss of mitochondria. Biochemical Journal 107, 455-465.

Criddle, R. S. \& Schatz, G. (1969). Promitochondria of anaerobically grown yeast. Biochemistry 8, 322-334.

DANSKY, C. H. (1976). Environmentally induced changes in mitochondria and endoplasmic reticulum of Saccharomyces carlsbergensis yeast. Journal of Cell Biology 71, 123-135.

Dixon, G. Y. \& KornberG, H. L. (1959). Assay methods for key enzymes of the glyoxylate cycle. Biochemical Journal 72, 3P.

Duell, E. A., Inoue, S. \& UtTer, M. F. (1964). Isolation and properties of intact mitochondria from sphaeroplasts of yeast. Journal of Bacterio$\log y$ 88, $1762-1768$.

Duntze, W., Neumann, D., Gancedo, J. M., AtzPodien, W. \& Holzer, H. (1969). Studies on the regulation and localisation of the glyoxylate cycle enzymes in Saccharomyces cerevisiae. European Journal of Biochemistry 10, 83-89.

Fansler. B. \& Lowenstein, J. M. (1969). Aconitase from pig heart. Methods in Enzymology 13, 26-30.

Kersters, K. \& De Ley, J. (1966). Primary and secondary alcohol dehydrogenases from Gluconobacter. Methods in Enzymology 9, 346-354.

KITTo, G. B. (1969). Intra- and extramitochondrial malate dehydrogenases from chicken and tuna heart. Methods in Enzymclogy 13, 106-116.

Machado, A., Nunez de Castro, I. \& Mayor, F. (1975). Isocitrate dehydrogenases and oxoglutarate dehydrogenase activities of bakers yeast grown in a variety of hypoxic conditions. Molecular and Cellular Biochemistry 6, 93-100.

MASSEY, V. \& Singer, T. P. (1957). Succinate dehydrogenase. III. Fumaric reductase activity of succinate dehydrogenase. Journal of Biological Chemistry 228, 263-274.

Perlman, P. S. \& Mahler, H. D. (1974). Derepression of mitochondria and their enzymes in yeast. Regulatory aspects. Archives of Biochemistry and Biophysics 162, 248-271.

Polakis, E. S. \& Bartley, W. (1965). Changes in the enzyme activities of Saccharomyces cerevisiae during aerobic growth on different carbon sources. Biochemical Journal 97, 284-302.

RACKER, E. (1950). Spectrophotometric measurement of the enzymic formation of fumaric and cis-aconitic acids. Biochimica et biophysica acta 4, 211-214.

REED, L. J. \& WILLMS, C. R. (1966). Determination and resolution of the pyruvate dehydrogenase complex. Methods in Enzymology 9, 247-265.

Schatz, G. (1965). Subcellular particles carrying mitochondrial enzymes in anaerobically grown cells of Saccharomyces cerevisiae. Biochimica et biophysica acta 96, 342-345.

Singer, S. J. \& Nicholson, G. L. (1972). The fiuid mosaic model of the structure of cell membranes. Science 175, 720-731.

Srere, P. A., Brazil, H. \& Goren, L. (1963). Citrate condensing enzyme of pigeon breast muscle and moth flight muscle. Acta chemica scandinavica 17, s129-s134.

SYMONS, R. H. \& BURCOYNE, L. A. (1966). LLactate (cytochrome) dehydrogenase (crystalline, yeast). Methods in Enzymology 9, 314-315.

VARY, M. J., EDwards, C. L. \& Stewart, P. R. (1969). The biogenesis of mitochondria. Formation of the soluble mitochondrial enzymes malate dehydrogenase and fumarase in Saccharomyces cerevisiae. Archives of Biochemistry and Biophysics 130, 235-243. 